\title{
EXACT NULL CONTROLLABILITY OF ABSTRACT DIFFERENTIAL EQUATIONS BY FINITE-DIMENSIONAL CONTROL AND STRONGLY MINIMAL FAMILIES OF EXPONENTIALS
}

\author{
B. SHKLYAR
}

Abstract. The exact controllability to the origin for linear evolution control equation is considered. The problem is investigated by its transformation to infinite linear moment problem of generalized exponentials. The existence of solutions of obtained moment problem is investigated for the case when exponentials of a moment problem do not constitute a Riesz basis. The exact controllability of linear control system of neutral type is considered as an example.

Mathematics subject classification (2010): 34K06, 34K35, 93B05, 93B60, 93C23, 93C25.

Keywords and phrases: Abstract differential equations, exact controllability, moment problem, families of exponentials, functional differential equations.

\section{REFERENCES}

[1] N. Ahiezer, I. Glazman, Linear Operator Theory in Hilbert Spaces, Nauka Publishers, Moscow, 1966 (in Russian).

[2] S. Avdonin, A. Ivanov, Families of exponentials. The method of Moments in Controllability Problems for Distributed parameter Systems, Cambridge University Press, Cambridge, 1995.

[3] N. BARI, Biorthogonal sequences and bases in Hilbert spaces, Moskov. Gos. Univ. Učenye Zapiski Matematika, 148, 4 (1951), 69-107.

[4] R. Bellmann, K. Cooke, Differential-Difference Equations, Mathematics in Science and Engineering, Vol. 6, 1963.

[5] R. BoAs, A general moment problem, Amer. J. Math., 63 (1941), 361-370.

[6] H. FATTORINI, Some remark on complete controllability, SIAM J. Control., 4 (1966), 686-694.

[7] H. FATTORINI, D. RUSSEL, Uniform bounds on biorthogonal functions for real exponents with an application to the control theory of parabolic equations, Quart. Appl. Math., 32 (1974/75), 45-69.

[8] Gen Qi XU, SiU PAng Yung, The expansion of a semigroup and a Riesz basis criterion, J. Differential Equations, 210 (2005), 1-24.

[9] I. GohberG, M. KREIN, Introduction to the Theory of Linear Nonselfadjoint operators, Translations of Mathematical Monographs, Vol. 18, American Mathematical Society, Providence 1969.

[10] J. Hale, Theory of Functional Differential Equations, Applied Mathematical Sciences, Vol. 3., Springer-Verlag, New York Heidelberg Berlin, 1977.

[11] E. Hille, R. Philips, Functional Analysis and Semi-Groups, rev. ed. American Mathematical Society Colloquium Publications, Vol. 31., American Mathematical Society, Providence, R. I., 1957.

[12] S. KaČMAŽ, H. Steinhaus, Theory of Orthogonal Series, Gosudarstv. Izdat. Fiz.-Mat. Lit., Moscow 1958

[13] J. Klamka, Controllability of Dynamical Systems, Mathematics and its Applications (East European Series), 48, Kluwer Academic Publishers Group, Dordrecht, Nederlands, 1991.

[14] J. Klamka, Constrained exact controllability of semilinear systems, Systems Control Lett., 47, 2 (2002), 139-147.

[15] J. KlamKa, Controllability of Dynamical Systems, Mat. Stosow., 9, 50 (2008), 57-75.

[16] M. Krein, Linear Differential Equations in Banach Spaces, Nauka Publishers, Moscow, 1967 (in Russian). 
[17] E. B. Lee, L. Markus, Foundations of Optimal Control Theory, John Wiley \& Sons, 1967.

[18] J. L. Lions, Contrôllabilité Exacte, perturbations et Stabilization de Systèmes Distribués, Recherches en Mathématiques Appliquées, Masson, Paris, 1988.

[19] M. MARKus, H. Minc, A Survey of Matrix Theory and Matrix Inequalities, Allyn and Bacon, Inc., Boston, 1964.

[20] M. NAimark, Linear differential Operators, Moscow, Nauka Publishers, 1969 (in Russian).

[21] R. RABAH, G. SKLYAR, The analysis of exact controllability of neutral-type systems by the moment problem approach, SIAM J. Control Optim., 36, 6 (2007), 2148-2181.

[22] D. Russel, Controllability and stabilizability theory for linear partial differential equations: Recent progress and open questions, SIAM Rev., 20, 4 (1978), 639-739.

[23] D. SALAMON, Infinite-dimensional linear systems with unbounded control and observation: a functional analytic approach, Trans. Amer. Math. Soc., 300 (1987), 383-431.

[24] A. M. SEDLETSKII, On biorthogonal expansions in exponential functions, Math. USSR Izv., 36 (1972), 583-590 (in Russian).

[25] D. UlLRICH, Divided differences and systems of nonharmonic Fourier series, Proc. Amer. Math. Soc., 80, 1 (1980), 47-57.

[26] N. Wiener, R. PAley, Fourier Transforms in the complex domain, American Mathematical Society Colloquium Publications, 19. , New York, 1934.

[27] V. Vlasov, On spectral problems arising in the theory of functional differential equations, Funct. Differ. Equ., 8 (2001), 435-446.

[28] G. WeISS, Admissibility of unbounded control operators, SIAM J. Control Optim., 27 (1989), $527-$ 545.

[29] R. Young, An introduction to nonharmonic Fourier series, Pure and Applied Mathematics, 93, Academic Press, Inc., New York-London, 1980.

[30] R. Young, On a class of Riesz-Fisher sequences, Proc. Amer. Math. Soc., 126, 4 (1998), 1139-1142. 